\title{
Performance of nanofluids on heat transfer in a wavy solar collector
}

\author{
Rehena Nasrin* and M. A. Alim \\ Department of Mathematics, Bangladesh University of Engineering \& Technology,Dhaka-1000, BANGLADESH \\ "Corresponding Author e-mail: rehena@math.buet.ac.bd
}

\begin{abstract}
The problem of steady, laminar and incompressible natural convection flow in a wavy solar collector is studied. In this investigation, two vertical walls are perfectly insulated. The top cover glass surface is continuously absorbing solar energy. The bottom wavy solid surface is kept at a constant temperature $T_{c}$. Numerical analysis is done by this article for the performance of different nanofluids on convective flow and heat transfer phenomena inside a solar collector. The solar collector has the flatplate cover and sinusoidal wavy absorber. Two different nanofluids like water based Ag nanofluid and water based $\mathrm{CuO}$ nanofluid are used as the working fluids inside the solar collector. The governing partial differential equations with proper boundary conditions are solved by Finite Element Method using Galerkin's weighted residual scheme. The behavior of both nanofluids related to performance such as temperature and velocity distributions, radiative and convective heat transfers, mean temperature and velocity of the nanofluid is investigated systematically. This performance includes the solid volume fraction namely $\phi$ with respect to water based $\mathrm{Ag}$ and water based $\mathrm{CuO}$ nanofluids. The results show that the better performance of heat transfer inside the collector is found by using the highest $\phi$ of water based Ag nanofluid.
\end{abstract}

Keywords: Free convection, wavy solar collector, finite element method, water based silver nanofluid and water based copper oxide nanofluid.

DOI: http://dx.doi.org/10.4314/ijest.v5i3.6

\section{Introduction}

Solar energy, radiant light and heat from the sun, has been harnessed by humans since ancient times using a range of everevolving technologies. Of all the sources of renewable energy especially solar energy has the greatest potential when other sources in the country have depleted. Because of the desirable environmental and safety aspects it is widely believed that solar energy should be utilized instead of other alternative energy forms, even when the costs involved are slightly higher. Solar energy technologies include solar heating, solar photovoltaics, solar thermal electricity and solar architecture, which can make considerable contributions to solving some of the most urgent problems the world now faces. Solar technologies are broadly characterized as either passive solar or active solar depending on the way they capture, convert and distribute solar energy. Active solar techniques include the use of photovoltaic panels and solar thermal collectors to harness the energy. Passive solar techniques include orienting a building to the Sun, selecting materials with favorable thermal mass or light dispersing properties, and designing spaces that naturally circulate air. The development of affordable, inexhaustible and clean solar energy technologies will have huge longer-term benefits. It will increase countries' energy security through reliance on an indigenous, inexhaustible and mostly import-independent resource, enhance sustainability, reduce pollution, lower the costs of mitigating climate change, and keep fossil fuel prices lower than otherwise. These advantages are global. Hence the additional costs of the incentives for early deployment should be considered learning investments; they must be wisely spent and need to be widely shared. The fluids with solid-sized nanoparticles suspended in them are called "nanofluids". The natural convection in enclosures continues to be a very active area of research during the past few decades. Applications of nanoparticles in thermal field are to enhance heat transfer from solar collectors to storage tanks, to improve efficiency of coolants in transformers. 
The analysis has been substantially assisted by the derivation of plate-fin efficiency factors. The factors relate the design and operating conditions of the collector in a systematic manner that facilitates prediction of heat collection rates at the design stage. The one-dimensional analysis offers a desired accuracy required in a routine analysis even though a two-dimensional temperature distribution exists over the absorber plate of the collector. Therefore, for more accurate analysis at low mass flow rates, a twodimensional temperature distribution must be considered. Various investigators have used two dimensional conduction equations in their analysis with different boundary conditions. Lund (1986) used a two-dimensional model for the transfer of heat in flat plate solar collector absorbers with adiabatic boundary conditions at the upper and lower edges of the collector. He solved approximately the governing partial differential equations analytically in terms of perturbation series.

Nag et al. (1989) used the two-dimensional model proposed by Lund, but with convection boundary condition at the upper and lower edge of the absorber plate. They solved the governing equations using finite element method. They concluded that the isotherms deviated from a one-dimensional pattern for a high flow rate to a predominantly two-dimensional distribution for a low mass flow rate. Conventional analysis and design of solar collector is based on a one-dimensional conduction equation formulation Sukhatme (1991), Piao et al. (1994) investigated experimentally natural, forced and mixed convective heat transfer in a crosscorrugated channel solar air heater. Stasiek (1998) made experimental studies of heat transfer and fluid flow across corrugated and undulated heat exchanger surfaces. He concluded that the measuring technique comprising the use of LC flexible sheets and truecolour processing might be used for a great variety of applications and should be of considerable use in improving the design of all types of compact heat exchanger. Noorshahi et al. (1996) studied numerically the natural convection effect in a corrugated enclosure with mixed boundary conditions. Detailed experimental and numerical studies on the performance of the solar air heater were made by Gao (1996) where the transport equations are discretized on a non-uniform mesh with a finite volume, fully implicit scheme, and the discretized equations are then solved with the S.O.R (successive over relaxation) iterative method.

There are so many methods introduced to increase the efficiency of the solar water heater (Xiaowu and Hua, 2005; Xuesheng et al., 2005; Ho and Chen, 2006; Hussain, 2006). But the novel approach is to introduce the nanofluids in solar water heater instead of conventional heat transfer fluids (like water). The poor heat transfer properties of these conventional fluids compared to most solids are the primary obstacle to the high compactness and effectiveness of the system. The essential initiative is to seek the solid particles having thermal conductivity of several hundred times higher than those of conventional fluids. An innovative idea is to suspend ultra fine solid particles in the fluid for improving the thermal conductivity of the fluid by Hetsroni and Rozenblit (1994). These early studies, however, used suspensions of millimeter- or micrometer-sized particles, which, although showed some enhancement, experienced problems such as poor suspension stability and hence channel clogging, which are particularly serious for systems using mini sized and micro sized particles. The suspended metallic or nonmetallic nanoparticles change the transport properties and heat transfer characteristics of the base fluid. Hwang et al. (2007) studied the stability and thermal conductivity characteristics of nanofluids. In this study, they concluded that the thermal conductivity of ethylene glycol was increased by $30 \%$.

The absorptance of the collector surface for shortwave solar radiation depends on the nature and colour of the coating and on the incident angle. Usually black colour is used. Various colour coatings had been proposed in Tripanagnostopoulos et al. (2000), Orel et al. (2002) and Wazwaz et al. (2002) mainly for aesthetic reasons. A low-cost mechanically manufactured selective solar absorber surface method had been proposed by Konttinen et al. (2003). Another category of collectors is the uncovered or unglazed solar collector by Soltau (1992). These are usually low-cost units which can offer cost effective solar thermal energy in applications such as water preheating for domestic or industrial use, heating of swimming pools of Molineaux et al. (1994), space heating and air heating for industrial or agricultural applications. The principal requirement of the solar collector is a large contact area between the absorbing surface and the air. Various applications of solar air collectors were reported by Kolb et al. (1999).

Kent (2009) studied laminar natural convection in isosceles triangular enclosures for cold base and hot inclined walls numerically. Effects of Rayleigh number and aspect ratio on the flow field and heat transfer were analyzed. Results showed that the enclosures with a low aspect ratio had higher heat transfer rates from the bottom surface of the triangular enclosure. A numerical experiment is performed for inclined solar collectors by Varol and Oztop (2007). Results indicated that heat transfer was increased with increasing Rayleigh number and aspect ratio, and was decreased with increasing wavelength. Bég et al. (2011) performed non-similar mixed convection heat and species transfer along an inclined solar energy collector surface with cross diffusion effects, where the resulting governing equations were transformed and then solved numerically using the local nonsimilarity method and Runge-Kutta shooting quadrature. Nasrin et al. (2012,a,b,c,d, 2013) analyzed effective heat transfer phenomena by different nanofluids on natural convection inside different geometries. Here the authors solved the governing partial differential equations with proper boundary conditions by the Finite Element Method using Galerkin's weighted residual scheme.

Khanafer and Vafai (2011) studied thermophysical characteristics of nanofluids. Ahmad and Pop (2010) as well as Ahmad et al. (2011) analyzed mixed convection boundary layer flow from a vertical flat plate embedded in a porous medium filled with nanofluids as well as Blasius and Sakiadis problems in nanofluids. Rohni et al. $(2011,2012)$ investigated boundary layer flow over a moving surface in a nanofluid beneath a uniform free stream and flow and heat transfer over an unsteady shrinking sheet with suction in nanofluids. Uddin et al. (2012) performed flow of a nanofluid from a convectively heated vertical plate with linear momentum slip boundary condition. Rosca et al. (2012) conducted non-Darcy mixed convection from a horizontal plate embedded in a nanofluid saturated porous media. Bachok et al. $(2010,2012)$ studied flow and heat transfer at a general three dimensional stagnation point as well as on a moving plate in a nanofluid. Das et al. (2007) investigated properties of nanofluids on science and technology. Kakaç and Pramuanjaroenkij (2009) reviewed convective heat transfer enhancement with nanofluids. Wong and Leon 
(2010) showed various applications of nanofluids on current and future. Saidur et al. (2011) also reviewed the performance of nanoparticles suspended with refrigerants and lubricating oils in refrigeration systems. Mahian et al. (2013) reviewed the applications of nanofluids in solar energy.

From the above literature review, it is mentioned that few numerical or experimental work has been done introducing different nanofluids. No work has been done about the performances of different nanofluids on convective phenomena. In this paper, we want to compare the performances of different nanofluids such as water- $\mathrm{Ag}$ and water-CuO nanofluids for the natural convective flow inside the solar collector having sinusoidal-wave absorber. So, the objective of this article is to present flow and heat transfer phenomena by different nanofluids and compare their performances inside a solar collector.

\section{Problem Formulation}

Fig. 1 shows a schematic diagram of a solar collector. The fluids in the collector are water-based nanofluids containing Ag and $\mathrm{CuO}$ nanoparticles. The nanofluids are assumed incompressible and the flow is considered to be laminar. It is considered that water and nanoparticles are in thermal equilibrium and no slip occurs among them. If the cold water enters under the path of the wavy absorber then it becomes hot with contact of the absorber. Then this hot water can be used for household's usage or various purposes. The solar collector is a metal box with a glass cover plate on the top surface and a dark colored undulating absorber plate on the bottom. It is assumed that both the nanoparticles are spherical shaped and diameters are less than $10 \mathrm{~nm}$. The bottom wavy wall is uniformly maintained at a constant temperature $T_{c}$. The top transparent surface is continuously absorbing solar energy. The density of the nanofluid is approximated by the Boussinesq model. Amplitude of wave $A_{m}=0.04$ and number of wave $\lambda=3.5$ are assumed. $L$ and $H$ are the length and average height of this physical model.

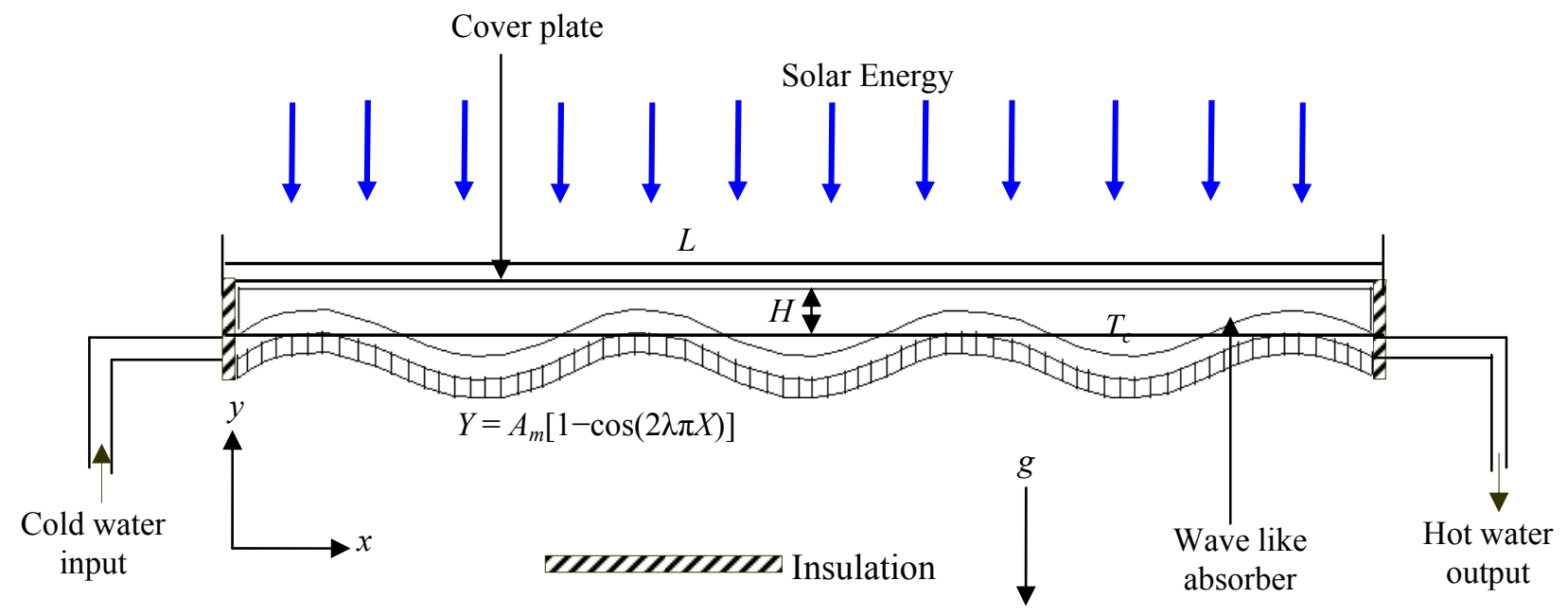

Fig.1. Schematic diagram of the Solar Collector

The governing equations for steady laminar natural convection inside a solar collector filled with water-Ag and water-CuO nanofluids in terms of the Navier-Stokes and energy equation (dimensional form) are taken from Lin and Violi (2010) and given as:

Continuity equation:

$$
\frac{\partial u}{\partial x}+\frac{\partial v}{\partial y}=0
$$

$x$-momentum equation:

$$
\rho_{n f}\left(u \frac{\partial u}{\partial x}+v \frac{\partial u}{\partial y}\right)=-\frac{\partial p}{\partial x}+\mu_{n f}\left(\frac{\partial^{2} u}{\partial x^{2}}+\frac{\partial^{2} u}{\partial y^{2}}\right)
$$

$\mathrm{y}$-momentum equation: 


$$
\rho_{n f}\left(u \frac{\partial v}{\partial x}+v \frac{\partial v}{\partial y}\right)=-\frac{\partial p}{\partial y}+\mu_{n f}\left(\frac{\partial^{2} v}{\partial x^{2}}+\frac{\partial^{2} v}{\partial y^{2}}\right)+g(\rho \beta)_{n f}\left(T-T_{c}\right)
$$

Energy equation:

$$
u \frac{\partial T}{\partial x}+v \frac{\partial T}{\partial y}=\alpha_{n f}\left(\frac{\partial^{2} T}{\partial x^{2}}+\frac{\partial^{2} T}{\partial y^{2}}\right)
$$

where, the density $\rho_{n f}=(1-\phi) \rho_{f}+\phi \rho_{s}$

the heat capacitance $\left(\rho C_{p}\right)_{n f}=(1-\phi)\left(\rho C_{p}\right)_{f}+\phi\left(\rho C_{p}\right)_{s}$

the thermal expansion coefficient $(\rho \beta)_{n f}=(1-\phi)(\rho \beta)_{f}+\phi(\rho \beta)_{s}$

the thermal diffusivity $\alpha_{n f}=k_{n f} /\left(\rho C_{p}\right)_{n f}$

In the current study, the effective viscosity of the nanofluid is considered by the Pak and Cho correlation (1998). This correlation is given as modified form

$$
\mu_{n f}=\mu_{f}\left\{1+39.11 \phi+533.9 \phi^{2}\right\}
$$

Also the effective thermal conductivity (modified form) is used from Maxwell Garnett (MG) model (1904)

$$
k_{n f}=k_{f} \frac{k_{s}+2 k_{f}-2 \phi\left(k_{f}-k_{s}\right)}{k_{s}+2 k_{f}+\phi\left(k_{f}-k_{s}\right)}
$$

Radiation heat transfer by the glass cover surface must account for thermal radiation which can be absorbed, reflected, or transmitted. This decomposition can be expressed by,

$$
q_{\text {net }}=q_{\text {absorbed }}+q_{\text {transmitted }}+q_{\text {reflected }}
$$

Outside the boundary layer, the amount of energy $q_{\text {reflected }}$ is neglected.

Thus total energy of the glass cover plate becomes $q_{\text {net }}=q_{\text {absorbed }}+q_{\text {transmitted }}$

Now the amount of transmitted energy is radiated from the cover plate as:

$$
q_{\text {transmitted }}=q_{r}=\varepsilon \sigma A\left(T_{w}^{4}-T_{i}^{4}\right)
$$

Here $\varepsilon$ is emissivity of the glass cover plate, $\sigma$ is Stefan Boltzmann constant $5.670400 \times 10^{-8} \mathrm{Js}^{-1} \mathrm{~m}^{-2} \mathrm{~K}^{-4}$ and $T_{w}$ is the variable temperature of the slant wall. Again, the amount of absorbed energy is transferred from cover plate to absorber by natural convection where medium is nanofluid as:

$$
q_{\text {absorbed }}=q_{c}=h A\left(T_{w}-T_{i}\right)
$$

So total energy gained or loosed by the cover plate is $q_{n e t}=h A\left(T_{w}-T_{i}\right)+\varepsilon \sigma A\left(T_{w}{ }^{4}-T_{i}^{4}\right)$

The boundary conditions are:

at all solid boundaries $u=v=0$

at the vertical walls $\frac{\partial T}{\partial x}=0$

at the top cover plate $q=h A\left(T_{w}-T_{i}\right)+\varepsilon \sigma A\left(T_{w}^{4}-T_{i}^{4}\right)$

at the bottom wavy absorber $T=T_{c}$

The above equations are non-dimensionalized by using the following dimensionless dependent and independent variables:

$$
X=\frac{x}{L}, \quad Y=\frac{y}{L}, \quad U=\frac{u L}{v_{f}}, \quad V=\frac{v L}{v_{f}}, \quad P=\frac{p L^{2}}{\rho_{f} v_{f}^{2}}, \theta=\frac{T-T_{c}}{T_{w}-T_{c}}
$$

Then the non-dimensional governing equations are 


$$
\begin{aligned}
& \frac{\partial U}{\partial X}+\frac{\partial V}{\partial Y}=0 \\
& U \frac{\partial U}{\partial X}+V \frac{\partial U}{\partial Y}=-\frac{\rho_{f}}{\rho_{n f}} \frac{\partial P}{\partial X}+\frac{v_{n f}}{v_{f}}\left(\frac{\partial^{2} U}{\partial X^{2}}+\frac{\partial^{2} U}{\partial Y^{2}}\right) \\
& U \frac{\partial V}{\partial X}+V \frac{\partial V}{\partial Y}=-\frac{\rho_{f}}{\rho_{n f}} \frac{\partial P}{\partial Y}+\frac{v_{n f}}{v_{f}}\left(\frac{\partial^{2} V}{\partial X^{2}}+\frac{\partial^{2} V}{\partial Y^{2}}\right)+\frac{R a}{P r} \frac{(1-\phi)(\rho \beta)_{f}+\phi(\rho \beta)_{s}}{\rho_{n f} \beta_{f}} \theta \\
& U \frac{\partial \theta}{\partial X}+V \frac{\partial \theta}{\partial Y}=\frac{1}{P r} \frac{\alpha_{n f}}{\alpha_{f}}\left(\frac{\partial^{2} \theta}{\partial X^{2}}+\frac{\partial^{2} \theta}{\partial Y^{2}}\right)
\end{aligned}
$$

where $\operatorname{Pr}=\frac{v_{f}}{\alpha_{f}}$ is the Prandtl number, $R a=\frac{g \beta_{f} L^{3}\left(T_{w}-T_{c}\right)}{v_{f} \alpha_{f}}$ is the Rayleigh number.

The corresponding boundary conditions take the following form:

at all solid boundaries $U=V=0$

at the vertical walls $\frac{\partial \theta}{\partial X}=0$

at the absorber surface $\theta=0$

at the top surface: non-dimensional heat flux

The shape of the bottom wavy absorber profile is assumed to mimic the following pattern $Y=A_{m}[1-\cos (2 \lambda \pi X)]$ where $A_{m}$ is the dimensionless amplitude of the wavy surface and $\lambda$ is the number of undulations.

\subsection{Average Nusselt number}

The average Nusselt number $(\mathrm{Nu})$ is expected to depend on a number of factors such as thermal conductivity, heat capacitance, viscosity, flow structure of nanofluids, volume fraction, dimensions and fractal distributions of nanoparticles.

The non-dimensional form of local convective heat transfer taken from Lin and Violi (2010) at the upper surface can be written as $\overline{N u}_{c}=-\frac{k_{n f}}{k_{f}} \frac{\partial \theta}{\partial Y}$.

By integrating the local convective Nusselt number over the top heated surface, the average convective heat transfer along the top wall of the solar collector is as $N u_{c}=\int_{0}^{1} \overline{N u_{c}} d X$.

The radiative heat transfer rate at the top cover plate is expressed as $N u_{r}=\int_{0}^{1} q_{r} d X$.

The average Nusselt number at the top surface is $N u=N u_{c}+N u_{r}$

For convenience, a normalized average Nusselt number is defined as the ratio of the average Nusselt number $(\mathrm{Nu})$ at any volume fraction of nanoparticles to that of the pure water, which are:

$$
N u^{*}(\phi)=\frac{N u(\phi)}{N u(\phi=0)} \text {. }
$$

The mean bulk temperature and average sub domain velocity of the fluid inside the collector may be written as

$$
\theta_{a v}=\int \theta d \bar{V} / \bar{V} \text { and } \omega_{a v}=\int \omega d \bar{V} / \bar{V} \text {, where } \bar{V} \text { is the volume of the collector. }
$$

\section{Numerical Implementation}

The Galerkin finite element method (Taylor and Hood, 1973; Dechaumphai, 1999) is used to solve the non-dimensional governing equations along with boundary conditions for the considered problem. The equation of continuity has been used as a constraint due to mass conservation and this restriction may be used to find the pressure distribution. This method is used to solve the Eqs. (13) - (15), where the pressure $P$ is eliminated by a constraint $\xi$, and the incompressibility criteria given by equation (12) which can be expressed as 


$$
P=-\xi\left(\frac{\partial U}{\partial X}+\frac{\partial V}{\partial Y}\right)
$$

The continuity equation is automatically fulfilled for large values of $\xi$. Then the velocity components $(U, V)$, and temperature $(\theta)$ are expanded using a basis set

$$
\{\Phi\}_{k=1}^{N} \text { as } U \approx \sum_{k=1}^{N} U_{k} \Phi_{k}(X, Y), \quad V \approx \sum_{k=1}^{N} V_{k} \Phi_{k}(X, Y) \text { and } \quad \theta \approx \sum_{k=1}^{N} \theta_{k} \Phi_{k}(X, Y)
$$

The Galerkin finite element technique yields the subsequent nonlinear residual equations for the Eqs. (13), (14) and (15) respectively at nodes of the internal domain $\Omega$ :

$$
\begin{aligned}
& R_{i}^{(1)}=\sum_{k=1}^{N} U_{k} \int_{\Omega}\left[\left(\sum_{k=1}^{N} U_{k} \Phi_{k}\right) \frac{\partial \Phi_{k}}{\partial X}+\left(\sum_{k=1}^{N} V_{k} \Phi_{k}\right) \frac{\partial \Phi_{k}}{\partial Y}\right] \Phi_{i} d X d Y- \\
& \xi \frac{\rho_{f}}{\rho_{n f}}\left[\sum_{k=1}^{N} U_{k} \int_{\Omega} \frac{\partial \Phi_{i}}{\partial X} \frac{\partial \Phi_{k}}{\partial X} d X d Y+\sum_{k=1}^{N} V_{k} \int_{\Omega} \frac{\partial \Phi_{i}}{\partial Y} \frac{\partial \Phi_{k}}{\partial Y} d X d Y\right]- \\
& \frac{v_{n f}}{v_{f}} \sum_{k=1}^{N} U_{k} \int_{\Omega}\left[\frac{\partial \Phi_{i}}{\partial X} \frac{\partial \Phi_{k}}{\partial X}+\frac{\partial \Phi_{i}}{\partial Y} \frac{\partial \Phi_{k}}{\partial Y}\right] d X d Y \\
& R_{i}^{(2)}=\sum_{k=1}^{N} V_{k} \int_{\Omega}\left[\left(\sum_{k=1}^{N} U_{k} \Phi_{k}\right) \frac{\partial \Phi_{k}}{\partial X}+\left(\sum_{k=1}^{N} V_{k} \Phi_{k}\right) \frac{\partial \Phi_{k}}{\partial Y}\right] \Phi_{i} d X d Y- \\
& \xi \frac{\rho_{f}}{\rho_{n f}}\left[\sum_{k=1}^{N} U_{k} \int_{\Omega} \frac{\partial \Phi_{i}}{\partial X} \frac{\partial \Phi_{k}}{\partial X} d X d Y+\sum_{k=1}^{N} V_{k} \int_{\Omega} \frac{\partial \Phi_{i}}{\partial Y} \frac{\partial \Phi_{k}}{\partial Y} d X d Y\right]- \\
& \frac{v_{n f}}{v_{f}} \sum_{k=1}^{N} V_{k} \int_{\Omega}\left[\frac{\partial \Phi_{i}}{\partial X} \frac{\partial \Phi_{k}}{\partial X}+\frac{\partial \Phi_{i}}{\partial Y} \frac{\partial \Phi_{k}}{\partial Y}\right] d X d Y- \\
& \frac{R a}{P r} \frac{(1-\phi)(\rho \beta)_{f}+\phi(\rho \beta)_{s}}{\rho_{n f} \beta_{f}} \int_{\Omega}\left(\sum_{k=1}^{N} \theta_{k} \Phi_{k}\right) \Phi_{i} d X d Y \\
& R_{i}^{(3)}=\sum_{k=1}^{N} \theta_{k}\left[\left(\sum_{\Omega}^{N} U_{k} \Phi_{k}\right) \frac{\partial \Phi_{k}}{\partial X}+\left(\sum_{k=1}^{N} V_{k} \Phi_{k}\right) \frac{\partial \Phi_{k}}{\partial Y}\right] \Phi_{i} d X d Y- \\
& \frac{1}{\operatorname{Pr}} \frac{\alpha_{n f}}{\alpha_{f}} \sum_{k=1}^{N} \theta_{k} \int_{\Omega}\left[\frac{\partial \Phi_{i}}{\partial X} \frac{\partial \Phi_{k}}{\partial X}+\frac{\partial \Phi_{i}}{\partial Y} \frac{\partial \Phi_{k}}{\partial Y}\right] d X d Y
\end{aligned}
$$

Three points Gaussian quadrature is used to evaluate the integrals in these equations. The non-linear residual equations (18), (19) and (20) are solved using Newton-Raphson method to determine the coefficients of the expansions in Eq. (17). The convergence of solutions is assumed when the relative error for each variable between consecutive iterations is recorded below the convergence criterion $\varepsilon$ such that $\left|\Psi^{n+1}-\Psi^{n}\right| \leq 10^{-4}$, where $n$ is the number of iteration and $\Psi$ is a function of $U, V$ and $\theta$. For numerical computation and post processing we use the Comsol Multiphysics and Tecplot software respectively.

\subsection{Mesh Generation}

In the finite element method, the mesh generation is the technique to subdivide a domain into a set of sub-domains, called finite elements, control volume, etc. The discrete locations are defined by the numerical grid, at which the variables are to be calculated. It is basically a discrete representation of the geometric domain on which the problem is to be solved. The computational domains with irregular geometries by a collection of finite elements make the method a valuable practical tool for the solution of boundary value problems arising in various fields of engineering. Fig. 2 displays the finite element mesh of the present physical domain. Here the computational domain is discretized into unstructured triangles. 


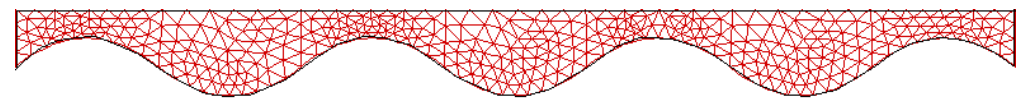

\subsection{Grid Independent Test}

Fig. 2: Mesh generation of the collector

An extensive mesh testing procedure is conducted to guarantee a grid-independent solution for $\operatorname{Pr}=6.2, R a=10^{5}$ and $\phi=5 \%$ in a solar collector. In the present work, we examine five different non-uniform grid systems with the following number of elements within the resolution field: $2880,4830,6516,8157$ and 10482 . The numerical scheme is carried out for highly precise key in the average convective and radiated Nusselt numbers namely $N u_{c}$ and $N u_{r}$ for the aforesaid elements to develop an understanding of the grid fineness as shown in Table 1. The scale of the average Nusselt number (convective and radiative) for 8157 elements shows a little difference with the results obtained for the other elements. Hence, considering the non-uniform grid system of 8157 elements is preferred for the computation.

Table 1: Grid Sensitivity Check at $\operatorname{Pr}=6.2, \phi=5 \%$ and $R a=10^{5}$

\begin{tabular}{|c|c|c|c|c|c|}
\hline $\begin{array}{c}\text { Nodes } \\
(\text { elements })\end{array}$ & $\begin{array}{c}4320 \\
(2880)\end{array}$ & $\begin{array}{c}7982 \\
(4830)\end{array}$ & $\begin{array}{c}12538 \\
(6516)\end{array}$ & $\begin{array}{c}17295 \\
(8157)\end{array}$ & $\begin{array}{c}21524 \\
(10482)\end{array}$ \\
\hline$N u_{c}$ & 9.82945 & 11.98176 & 12.77701 & 13.074711 & 13.084715 \\
\hline$N u_{r}$ & 4.32945 & 5.98176 & 6.68701 & 7.104909 & 7.114910 \\
\hline Time (s) & 248.265 & 301.594 & 395.157 & 482.328 & 618.375 \\
\hline
\end{tabular}

\subsection{Code Validation}

The present numerical solution is validated by comparing the current code results for heat transfer - temperature difference profile at $P r=0.73, G r=10^{4}$ with the graphical representation of Gao et al. (2000) which was reported for heat transfer augmentation inside a channel between the flat-plate cover and sine-wave absorber of a cross-corrugated solar air heater. Fig. 3 demonstrates the above stated comparison. As shown in Fig. 4, the numerical solutions (present work and Gao et al. (2000) are in good agreement.

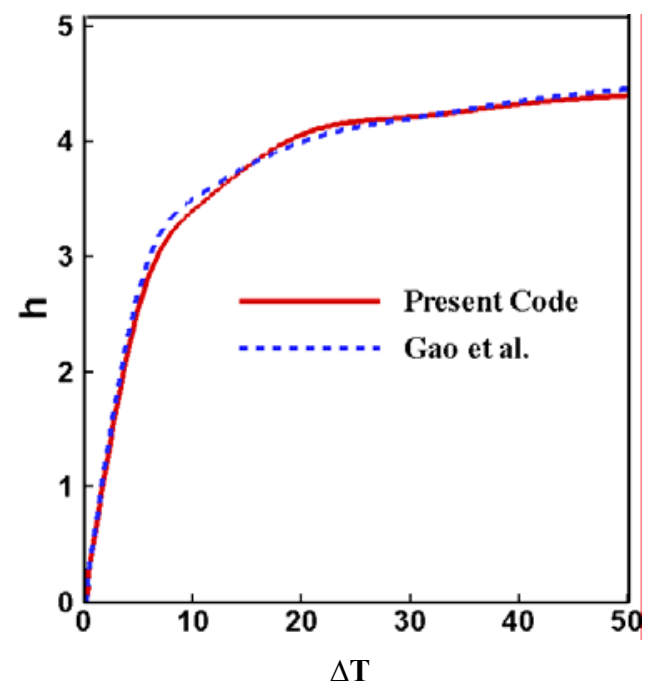

Fig. 3: Comparison between present code and Gao et al. (2000)

$$
\text { at } P r=0.73 \text { and } R a=10^{4}
$$


In addition, the current code results for streamlines and isotherms at $\operatorname{Pr}=0.71, A=2, L=2, \phi=40^{0}, R a=10^{6}$ with that of Varol and Oztop (2007) are compared and displayed by the Fig. 4. They studied Buoyancy induced heat transfer and fluid flow inside a tilted wavy solar collector.

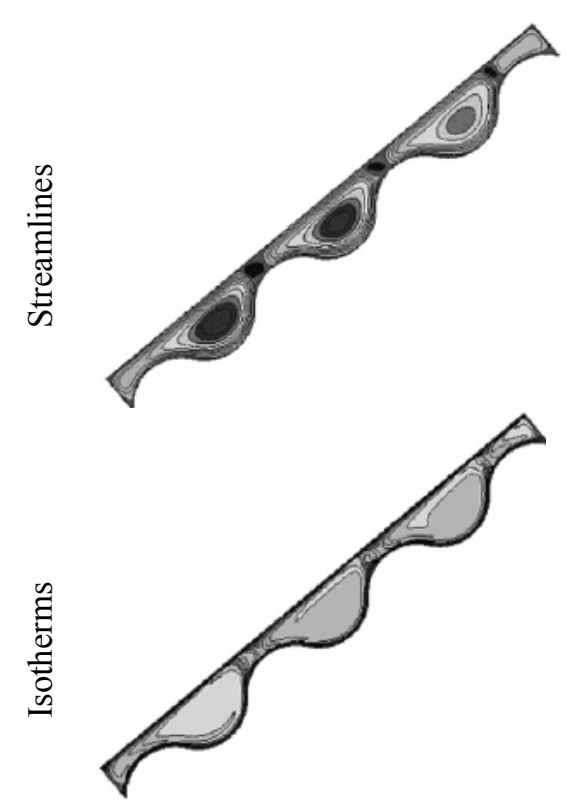

Varol and Oztop (2007)
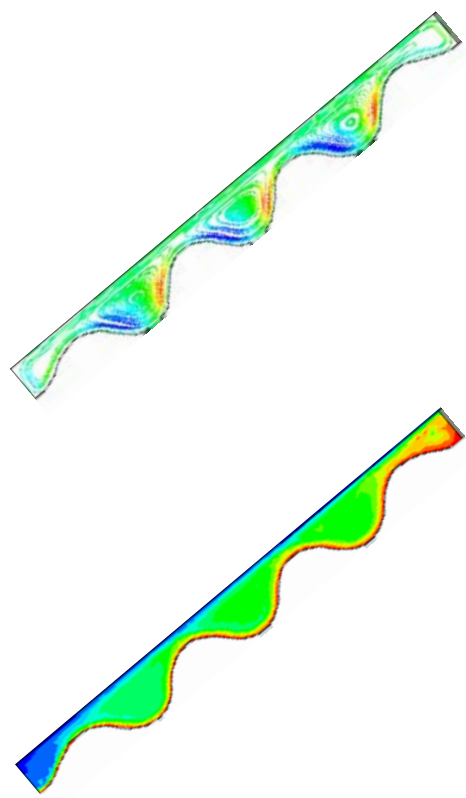

Present Work

Fig. 4: Comparison of present code with Varol and Oztop (2007)

\subsection{Thermophysical properties}

The thermophysical properties of the nanofluid are taken from Ogut (2009) and given in Table 2

Table 2: Thermo physical properties of base fluid and different nanoparticles

\begin{tabular}{cccc}
\hline Physical Properties & Fluid phase (Water) & $\mathrm{Ag}$ & $\mathrm{CuO}$ \\
\hline$C_{p}(\mathrm{~J} / \mathrm{kgK})$ & 4179 & 235 & 535.6 \\
$\rho\left(\mathrm{kg} / \mathrm{m}^{3}\right)$ & 997.1 & 10500 & 6500 \\
$k(\mathrm{~W} / \mathrm{mK})$ & 0.613 & 429 & 20 \\
$\alpha \times 10^{7}\left(\mathrm{~m}^{2} / \mathrm{s}\right)$ & 1.47 & 1738.6 & 57.45 \\
$\beta \times 10^{5}(1 / \mathrm{K})$ & 21 & 5.4 & 5.1 \\
$\mu \times 10^{6}\left(\mathrm{Ns} / \mathrm{m}^{2}\right)$ & 855 & - & - \\
\hline
\end{tabular}

\section{Results and Discussion}

In this section, numerical results of streamlines and isotherms for various values of solid volume fraction $(\phi)$ with $\mathrm{Ag} / \mathrm{water}$ and $\mathrm{CuO} /$ water nanofluids inside a solar collector are displayed. The considered values of $\phi$ are $\phi(=1 \%, 5 \%, 10 \%$ and $15 \%)$ while the Prandtl number $\operatorname{Pr}=6.2, R a=10^{5}$ and the emissivity $\varepsilon=0.98$ are kept fixed. In addition, the values of the average and normalized Nusselt number both for convection and radiation, mean bulk temperature and average velocity of different type of fluids (nanofluids and base fluid) as well as mid height horizontal and vertical velocities are shown graphically for the pertinent parameter. In the following Figures (5)-(8) the red colored solid lines and black colored dashed lines indicate the nanofluid and base fluid respectively.

The effect of solid volume fraction ( $\phi$ ) of water-Ag nanofluid on the thermal field is presented in Fig. 5 while $\operatorname{Pr}=6.2, R a=10^{5}$ and $\varepsilon=0.98$. The strength of the thermal current activities is more activated with escalating $\phi$. Isotherms are almost similar to the active parts for both $\mathrm{Ag}$ /water nanofluid and base fluid. Increasing $\phi$, the temperature lines at the middle part of the collector become horizontal whereas initially they are almost wavy pattern due to concentration of solid particles is dominated across the 
solar collector. With the rising values of $\phi$, the temperature distributions become distorted resulting in an increase in the overall heat transfer. This result can be attributed to the dominance of the solid concentration. This is because the thermal conductivity of the solid particles is higher than the clear water (without solid particles). This means that higher heat transfer rate is predicted by the water-Ag nanofluid than the base fluid $(\phi=0 \%)$. It is worth noting that as the solid volume fraction of Ag nanoparticles increases, the thickness of the thermal boundary layer near the top cover plate enhances which indicates a steep temperature gradients and hence, an increase in the overall heat transfer from the transparent cover plate to the wavelike absorber.
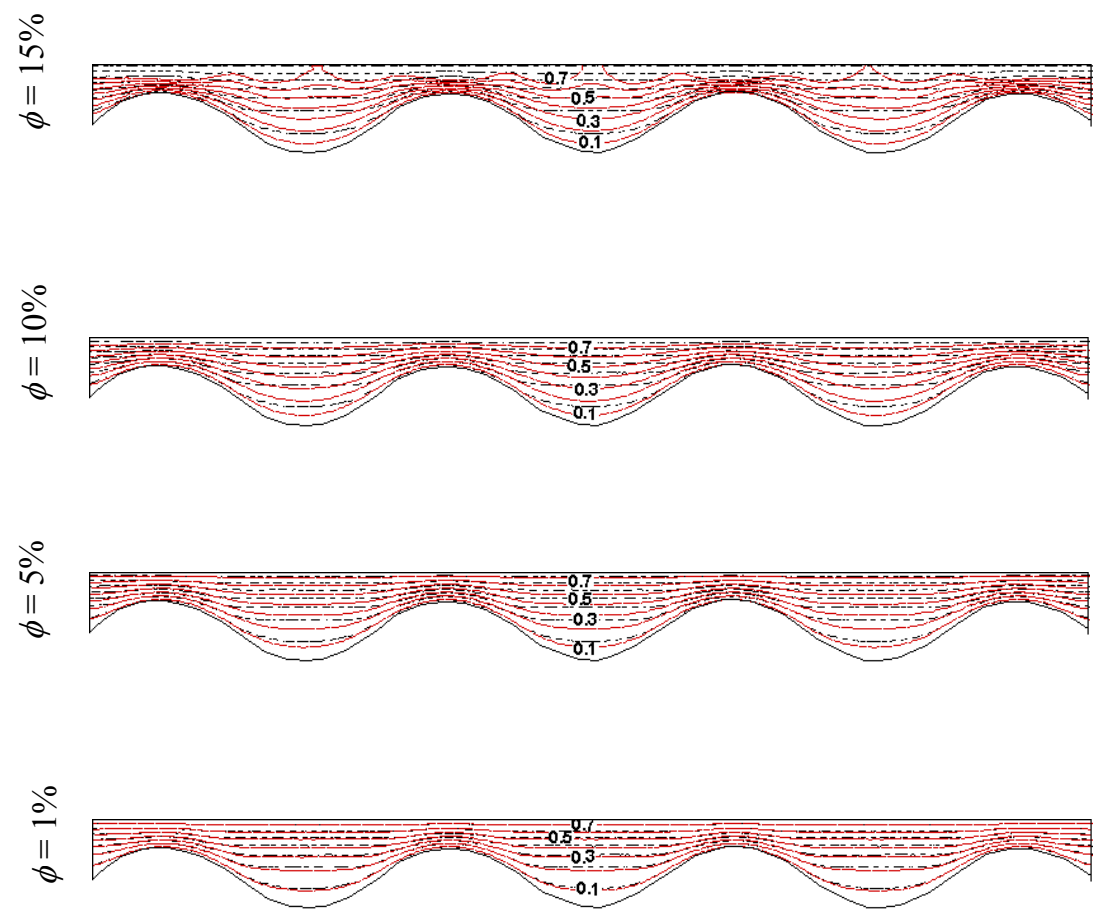

Fig. 5. Effect of $\phi$ of water-Ag nanofluid on isothermal lines

The corresponding velocity field is depicted in Fig. 6. For both type of fluids, six primary recirculation cells occupying the whole cavity is found at the lowest value of the solid volume fraction $(\phi=1 \%)$. As well as two tiny eddies appear near the left and right vertical walls in this case. In each wave, the right and left vortices rotate in counter clockwise and clockwise direction respectively. These cells are smaller for the water based nanofluid having silver nanoparticles than the clear water. This happens due to greater velocity of base fluid than nanofluid. For increasing $\phi$, velocity of working nanofluid decreases and thus size of the created eddies becomes smaller. In addition the developed tiny vortices disappear from the left and right top corners of the solar collector at $\phi=$ $15 \%$. This is expected because velocity of nanofluid with higher solid concentration diminishes slowly.

Fig. 7 exposes the heat transfer for various $\phi$ (solid volume fraction of water-CuO nanofluid) $R a=10^{5}, \operatorname{Pr}=6.2$ and $\varepsilon=0.98$. In this figure we observe that as the solid volume fraction of copper nanoparticles $\phi$ enhances from $1 \%$ to $15 \%$, the isothermal contours tend to get affected considerably. In addition, these lines corresponding to $\phi=10 \%$ become less bended whereas initially $(\phi=1 \%)$ the lines take sinusoidal wavelike form. The isotherms tend to gather near the bottom absorber of the solar collector due to comparatively higher temperature of the working $\mathrm{CuO}$ nanoparticles of nanofluid at the highest $\phi=15 \%$ where the contour lines mimic the wall's (absorber) profile. Rising solid volume fraction $\phi$ leads to deformation of the thermal boundary layer at the top cover plate. However, the increase in the thermal gradients at the absorber wavy wall is much higher for the considered nanofluid than for the clear water. This means that higher heat transfer rate is predicted by the nanofluid than the base fluid (water). 

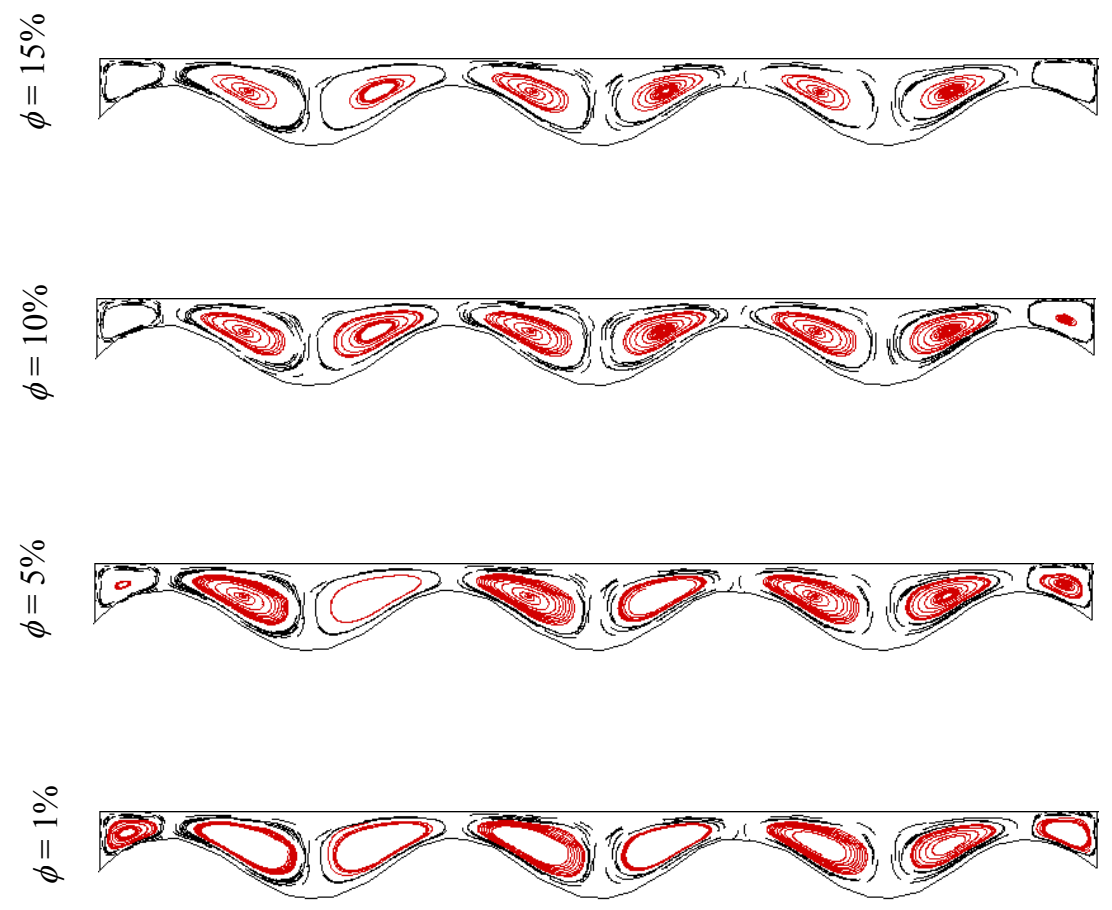

Fig. 6: Effect of $\phi$ of water-Ag nanofluid on streamlines
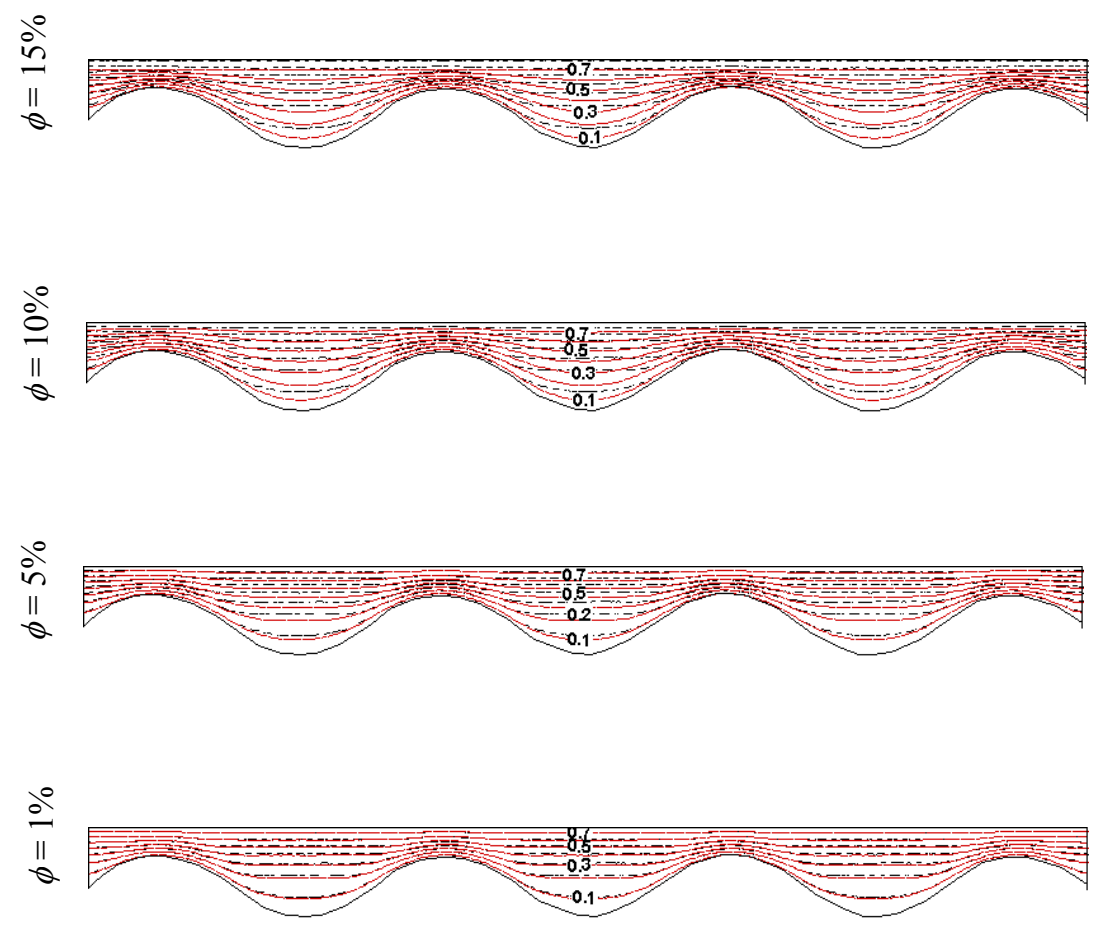

Fig. 7: Effect of $\phi$ of water-CuO nanofluid on isothermal lines 
The corresponding fluid flow represents in the Fig. 8. The streamlines cover the entire collector at the lowest $\phi$ forming few eddies. The change in the velocity field is similar to the Fig. 7. Due to rising solid volume fraction $(\phi)$ of the water based nanofluid with $\mathrm{CuO}$ nanoparticle the core of the vortices becomes slightly larger with comparison to that of Fig. 7 . This is due to the fact that density of $\mathrm{CuO}$ nanoparticle is lower than that of $\mathrm{Ag}$ nanoparticle. Nanofluid having larger density does not move rapidly.
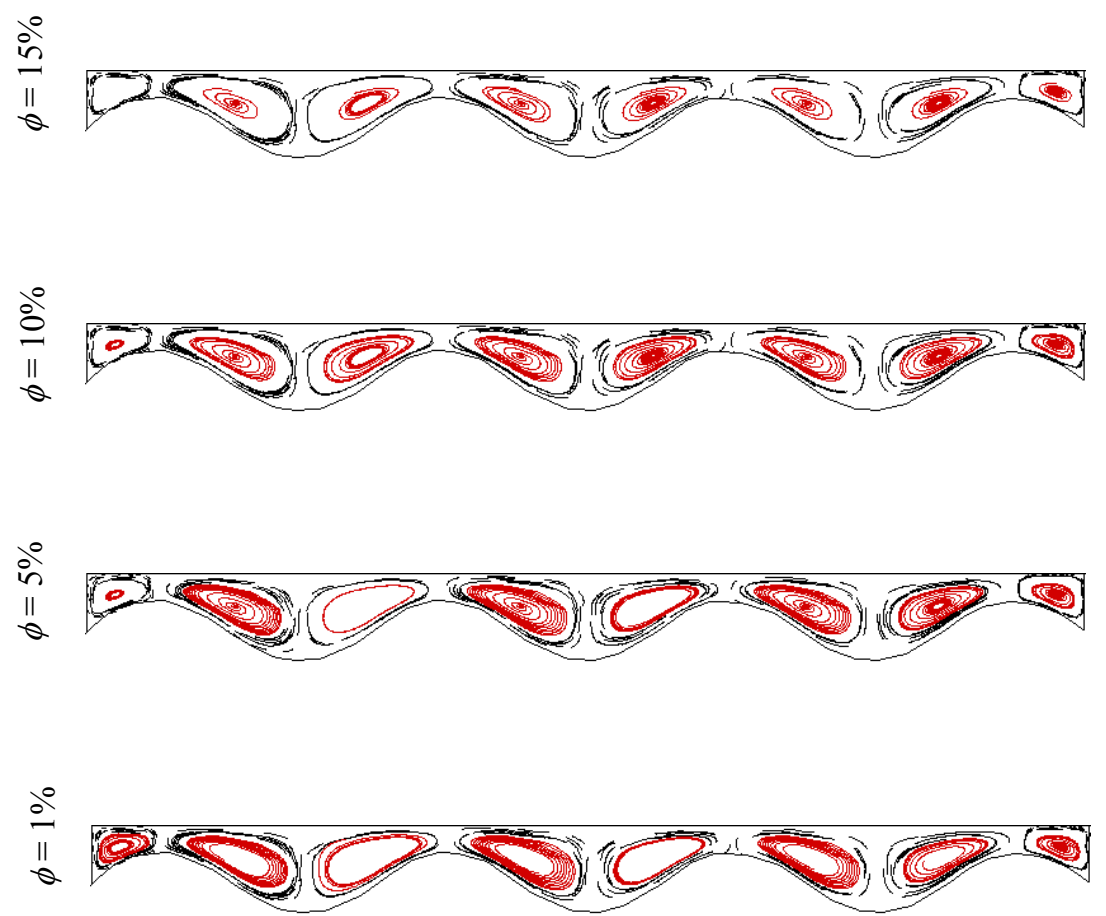

Fig. 8: Effect of $\phi$ of water-CuO nanofluid on streamlines

Fig. 9 (i)-(ii) displays the convective Nusselt number $\left(N u_{c}\right)$ for nanofluid and base fluid as well as radiative Nusselt number $\left(N u_{r}\right)$ for the effect of solid volume fraction of water-Ag and water-CuO nanofluids respectively. Mounting $\phi$ enhances average Nusselt number for both convection and radiation in the case of different nanofluids. But heat transfer rate is constant for base fluid $(\phi=$ $0 \%$ ) in these cases. From Fig. 9(i) it is observed that rate of convective heat transfer enhances by $26 \%$ whereas this rate for radiation is $14 \%$ with the increasing values of $\phi$ from $0 \%$ to $15 \%$. But from Fig. 9(ii) it is seen that these rates of heat transfer are respectively $14 \%$ and $6 \%$ with the growing $\phi$. The thermal conductivity of copper oxide nanoparticle is about twenty one times smaller than that of silver nanoparticle. That's why higher heat transfer rate is found by using water based Ag nanofluid.

Normalized Nusselt number $\mathrm{Nu}^{*}$ (convective and radiative) for the variation of solid volume fraction $(\phi)$ of silver and copper oxide nanoparticles of water based nanofluids is expressed in Fig. 10(i)-(ii). Both figures represent that $\mathrm{Nu}^{*}$ for convection is higher than that for radiation. It is well known that radiative heat transfer is always dominated by the convective heat transfer.

The mean temperature $\left(\theta_{a v}\right)$ of different type of fluids (base fluid and two nanofluids) inside the solar collector for the effect of solid volume fractions $(\phi)$ is displayed by the Fig. 11(i)-(ii). From this figure it is found that $\theta_{a v}$ for nanofluid grows with the variation of solid volume fraction for both nanofluids namely water-Ag and water-CuO. $\theta_{a v}$ for nanofluid is higher in Fig. 11(i) with compared to that of Fig. 11(ii). This is due to the fact that temperature of nanofluid rises for the higher thermal conductivity of silver nanoparticle than copper oxide nanoparticle.

Fig. 12(i)-(ii) exposes the average velocity $\left(\omega_{a v}\right)$ of both nanofluids and clear water in a corrugated solar collector. The mean velocity has notable changes with different values of solid volume fraction $(\phi)$. Here base fluid $(\phi=0 \%)$ has higher mean velocity than considered both nanofluids ( $\mathrm{Ag} /$ water and $\mathrm{CuO}$ /water). Clear water has constant mean velocity with the variation of $\phi$ in the Fig. 12(i)-(ii). 


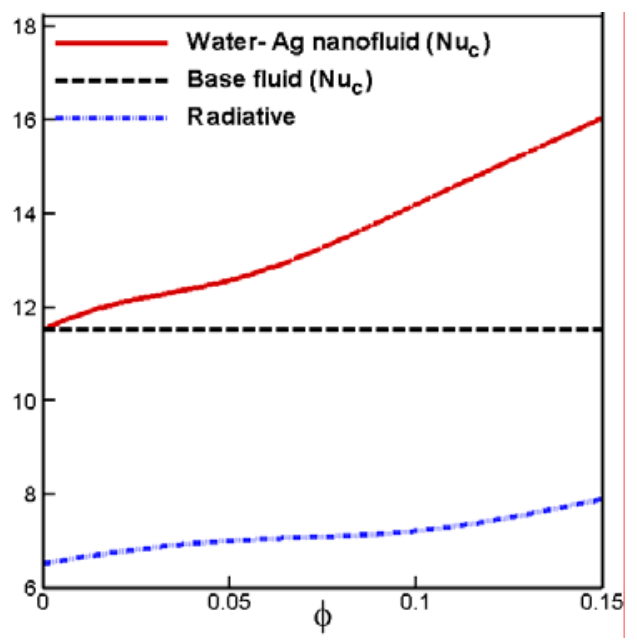

(i)

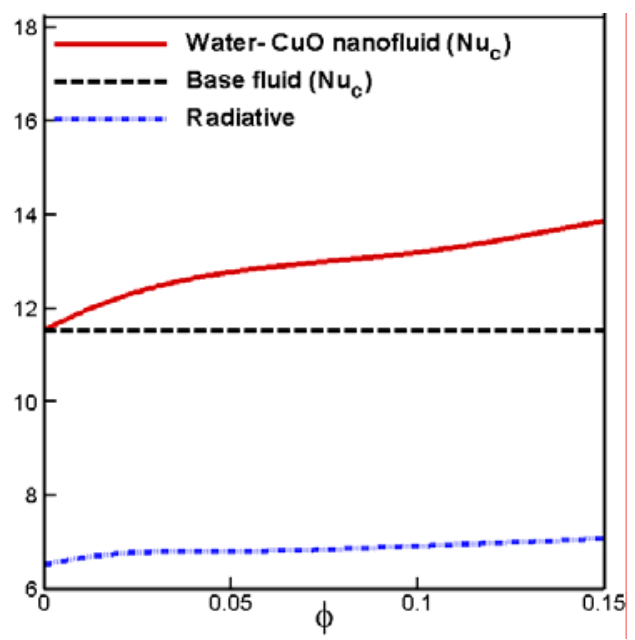

(ii)

Fig. 9: Rate of heat transfer for the effect of $\phi$ of (i) water-Ag nanofluid and (ii) water-CuO nanofluid 


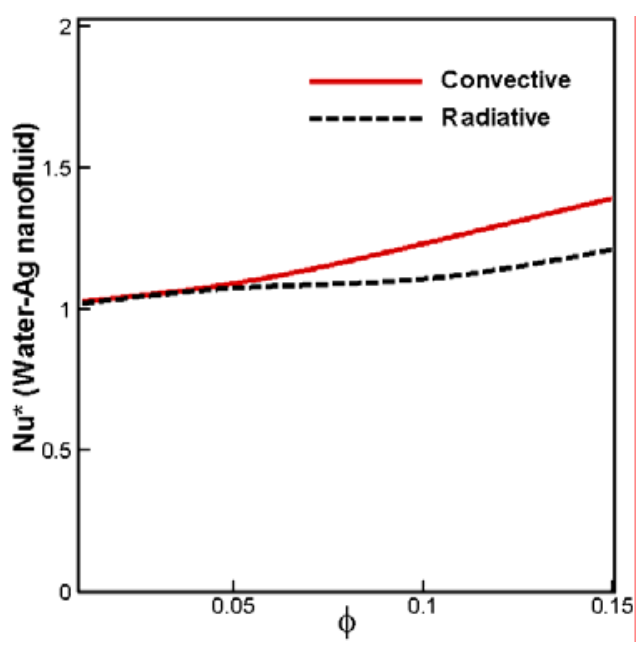

(i)

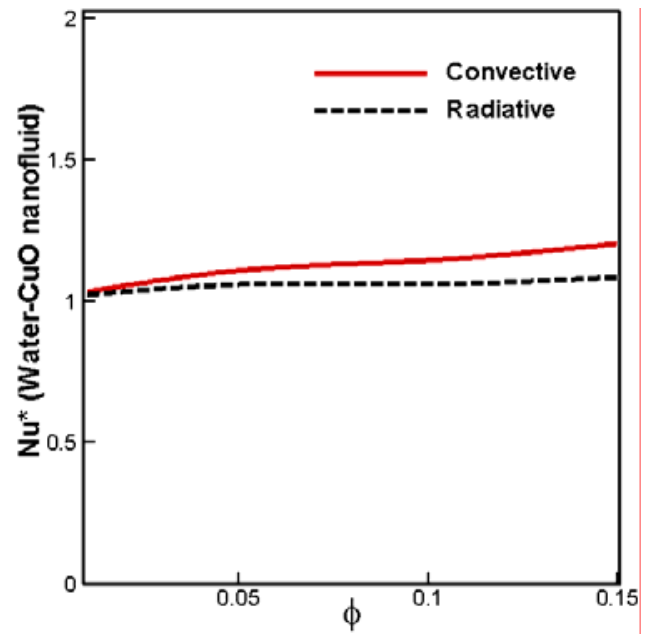

(ii)

Fig. 10: Effect of volume fraction variation on the $N u *$ (i) water- $\mathrm{Ag}$ nanofluid and (ii) water- $\mathrm{CuO}$ nanofluid 


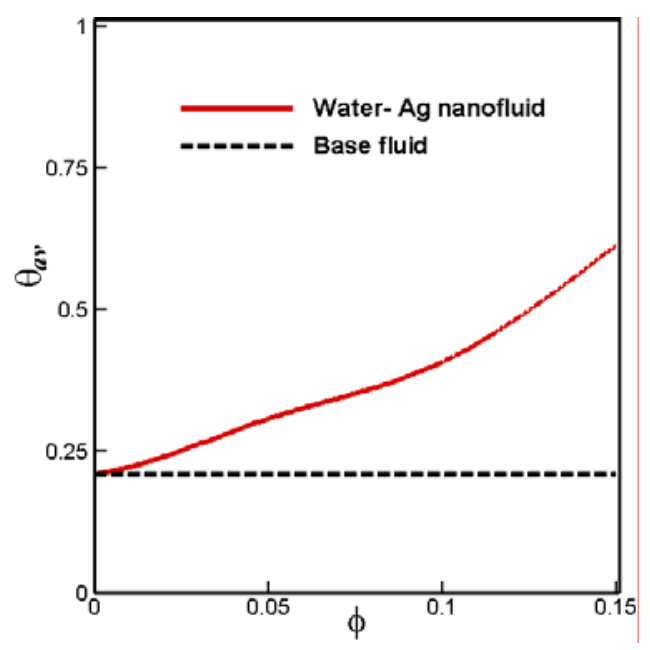

(i)

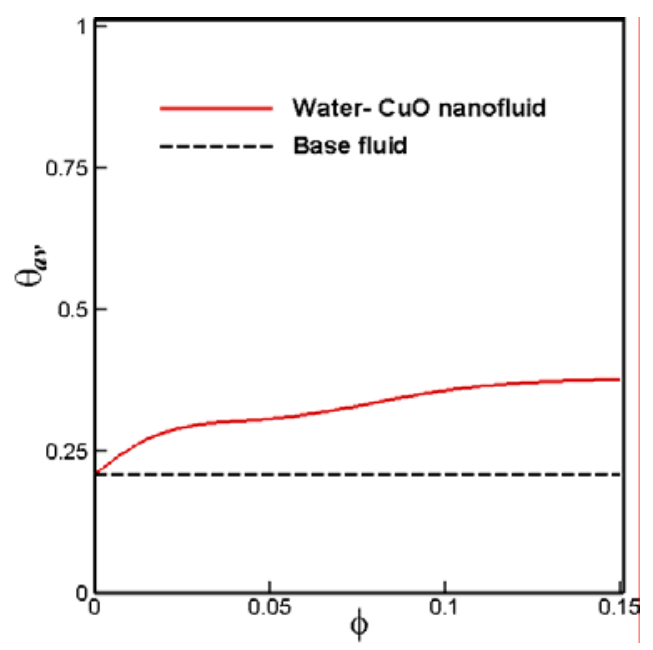

(ii)

Fig. 11: Effect of volume fraction variation on the mean temperature of nanofluids (i) water- $\mathrm{Ag}$ nanofluid and (ii) water- $\mathrm{CuO}$ nanofluid 


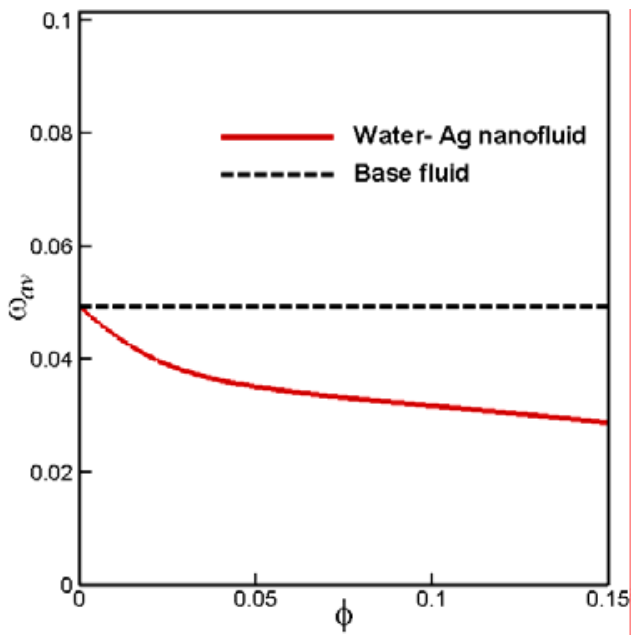

(i)

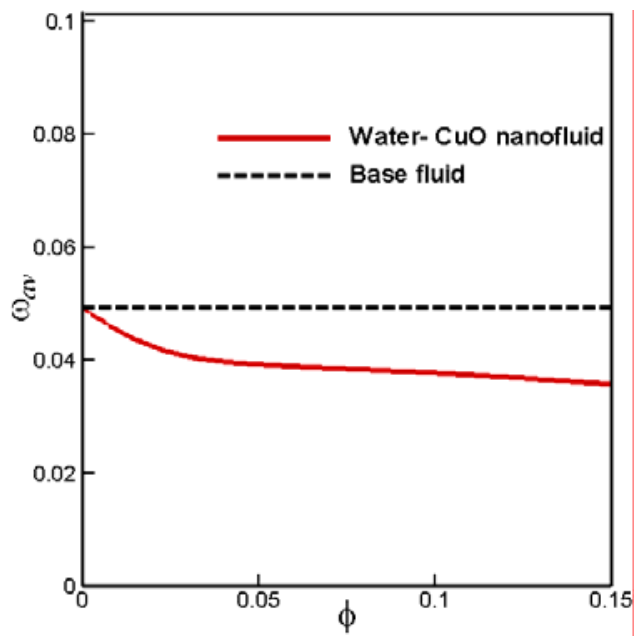

(ii)

Fig. 12: Effect of volume fraction variation on the average velocity of nanofluids (i) water- $\mathrm{Ag}$ nanofluid and (ii) water-CuO nanofluid 
The mid height horizontal $(U)$ velocity at $X=0.5$ of the solar collector for various $\phi$ is displayed in Fig. 13 (i)-(ii). Significant variation in velocity is found due to changing $\phi$. In the case of Fig. 13(ii) for the effect of $\phi$ (solid volume fraction of water-CuO nanofluid), some more perturbations are seen in the $U-Y$ graph with compared to the Fig. 13(i). It is desired that, copper oxide nanoparticle has lower density than that of silver nanoparticle.

The vertical $(V)$ velocity at the middle $(Y=0.05)$ of the solar collector for different $\phi$ effect is depicted in Fig. 14 (i)-(ii). It is observed that the water based $\mathrm{Ag}$ and water based $\mathrm{CuO}$ nanofluids move with lowest velocity for the highest value of solid volume fraction parameter. The waviness in the $V-X$ profile devalues for higher values of $\phi$.

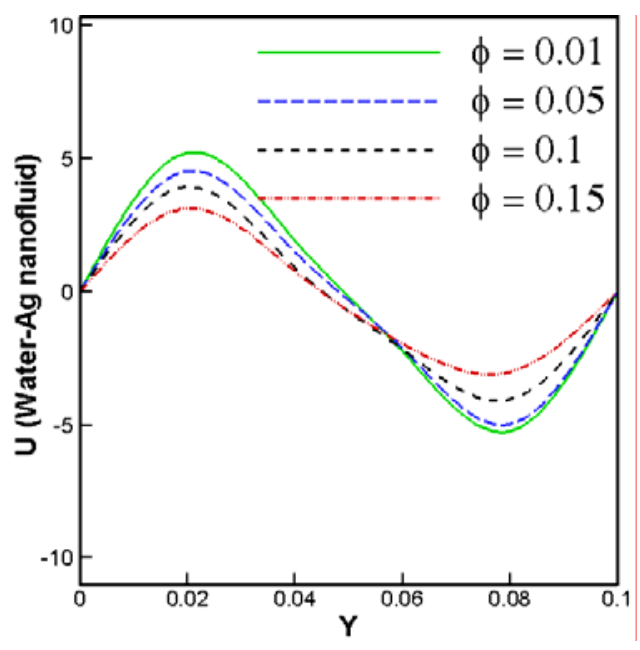

(i)

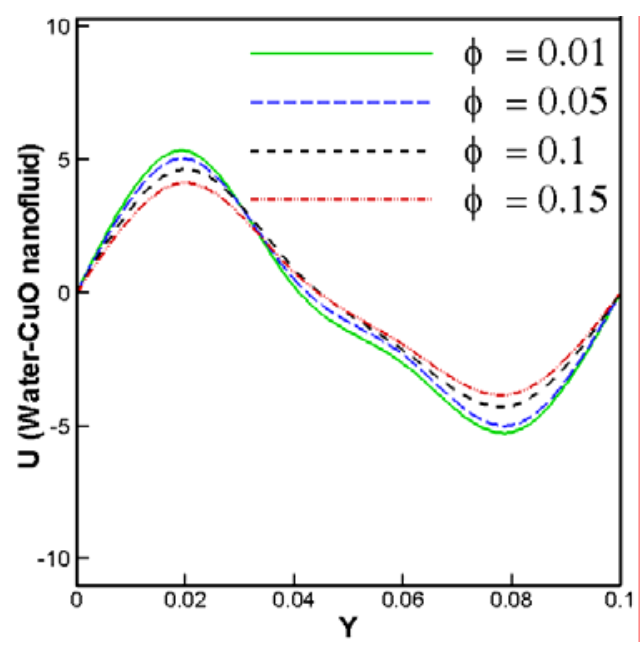

(ii)

Fig. 13: Effect of volume fraction variation on the mid height horizontal velocity (i) waterAg nanofluid and (ii) water-CuO nanofluid 


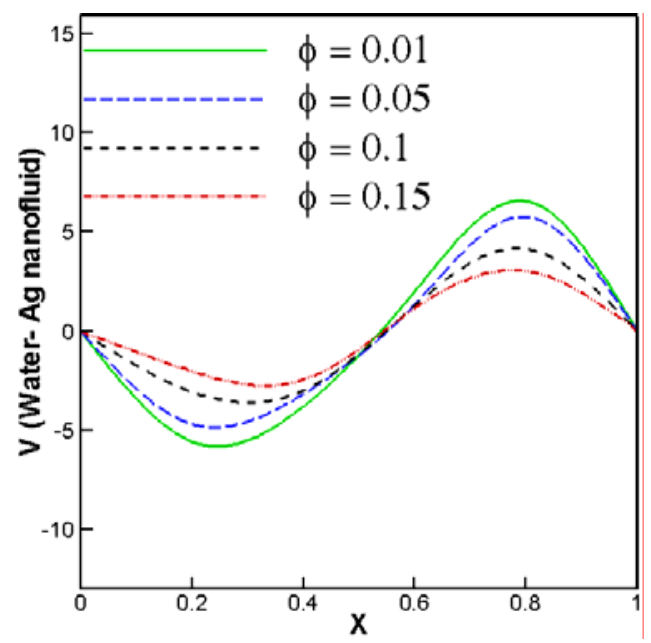

(i)

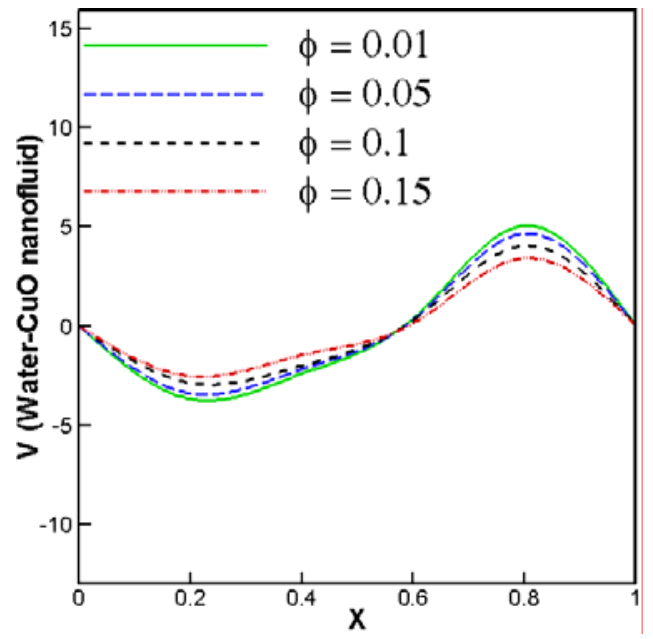

(ii)

Fig. 14: Effect of volume fraction variation on the mid height vertical velocity (i) water-Ag nanofluid and (ii) water-CuO nanofluid

\section{Conclusion}

The influences of solid volume fraction for different nanofluids on natural convection boundary layer flow inside a solar collector are accounted. Various solid volume fraction have been considered for the flow and temperature fields as well as the convective and radiative heat transfer rates, mid height horizontal and vertical velocities, mean bulk temperature of the fluids and average velocity field inside the wavy solar collector while $P r$ and $R a$ are fixed at 6.2 and $10^{5}$ respectively. The results of the numerical analysis lead to the following conclusions:

- The structure of the fluid streamlines and isotherms within the solar collector is found to significantly depend upon the solid volume fractions $\phi$ of water-Ag and water-CuO nanofluids.

- The $\mathrm{Ag} /$ water nanofluid with the highest $\phi$ are established to be more effective in enhancing performance of heat transfer rate than that of $\mathrm{CuO} /$ water nanofluid.

- Average heat transfer is obtained higher for convection than radiation.

- With growing $\phi$ mean temperature of water-Ag nanofluid raises more than water-CuO nanofluid.

- Average velocity field devalues due to growing $\phi$. 
- More considerable changes occur in the mid height horizontal and vertical velocity profiles for silver than copper oxide nanoparticles.

\section{Nomenclature}

$A \quad$ Area of glass cover plate $\left(\mathrm{m}^{2}\right)$

$A_{m} \quad$ Dimensionless amplitude of wave

$C_{p} \quad$ Specific heat at constant pressure $\left(\mathrm{kJ} \mathrm{kg}^{-1} \mathrm{~K}^{-1}\right)$

$g \quad$ Gravitational acceleration $\left(\mathrm{m} \mathrm{s}^{-2}\right)$

$h \quad$ Local heat transfer coefficient $\left(\mathrm{W} \mathrm{m}^{-2} \mathrm{~K}^{-1}\right)$

$H \quad$ Average height of the solar collector (m)

$k \quad$ Thermal conductivity $\left(\mathrm{W} \mathrm{m}^{-1} \mathrm{~K}^{-1}\right)$

$L \quad$ Length of the solar collector (m)

$\mathrm{Nu} \quad$ Nusselt number, $\mathrm{Nu}=h L / k_{f}$

$N u^{*} \quad$ Normalized Nusselt number, $N u^{*}(\phi)=\frac{N u(\phi)}{N u(\phi=0)}$

Pr Prandtl number, $\operatorname{Pr}=v_{f} / \alpha_{f}$

$R a \quad$ Rayleigh number, $R a=\frac{g \beta_{f} L^{3}\left(T_{w}-T_{c}\right)}{v_{f} \alpha_{f}}$

$T \quad$ Dimensional temperature $\left({ }^{\circ} \mathrm{K}\right)$

$T_{i} \quad$ Initial temperature of nanofluid $\left({ }^{\circ} \mathrm{K}\right)$

$u, v \quad$ Dimensional $x$ and $y$ components of velocity $\left(\mathrm{m} \mathrm{s}^{-1}\right)$

$U, V \quad$ Dimensionless velocities, $U=\frac{u L}{v_{f}}, \quad V=\frac{v L}{v_{f}}$

$X, Y \quad$ Dimensionless coordinates, $X=x / L, Y=y / L$

$x, y \quad$ Dimensional coordinates $(\mathrm{m})$

\section{Greek Symbols}

$\alpha \quad$ Fluid thermal diffusivity $\left(\mathrm{m}^{2} \mathrm{~s}^{-1}\right)$

$\beta \quad$ Thermal expansion coefficient $\left(\mathrm{K}^{-1}\right)$

$\varepsilon \quad$ Emissivity

$\theta \quad$ Dimensionless temperature, $\theta=\left(T-T_{c}\right) /\left(T_{w}-T_{c}\right)$

$\lambda \quad$ Number of wave

$\mu \quad$ Dynamic viscosity $\left(\mathrm{N} \mathrm{s} \mathrm{m}^{-2}\right)$

$v \quad$ Kinematic viscosity $\left(\mathrm{m}^{2} \mathrm{~s}^{-1}\right)$

$\rho \quad$ Density $\left(\mathrm{kg} \mathrm{m}^{-3}\right)$

$\sigma \quad$ Stefan Boltzmann constant

$\phi \quad$ Nanoparticles volume fraction

$\omega \quad$ Magnitude of dimensionless velocity

\section{Subscripts}

av average

c cold

$f \quad$ fluid

$h \quad$ hot

nf nanofluid

$s \quad$ solid particle

w cover plate

\section{References}

Ahmad, S, Rohni, AM, Pop, I, 2011. Blasius and Sakiadis problems in nanofluids, Acta Mechanica, Vol. 218, pp. 195-204.

Ahmad, S, Pop, I, 2010. Mixed convection boundary layer flow from a vertical flat plate embedded in a porous medium filled with nanofluids, Int. Commun. in Heat Mass Transfer, Vol. 37, pp. 987-991. 
Bachok, N, Ishak, A, Nazar, R and Pop, I, 2010. Flow and heat transfer at a general three dimensional stagnation point in a nanofluid, Physica B, Vol. 405, pp. 4914-4918.

Bachok, N, Ishak, A, and Pop, I, 2012. Flow and heat transfer characteristics on a moving plate in a nanofluid, Int. J. of Heat and Mass Transfer, Vol. 55, pp. 642-648.

Bég, OA., Bakier, A., Prasad, R., Ghosh, SK., 2011. Numerical modelling of non-similar mixed convection heat and species transfer along an inclined solar energy collector surface with cross diffusion effects, World Journal of Mechanics, Vol. 1, pp. 185-196.

Das, SK, Choi, SUS, Yu, W and Pradet, T, 2007. Nanofluids: Science and Technology, Wiley, New Jersey.

Dechaumphai, P., 1999. Finite Element Method in Engineering, 2nd ed., Chulalongkorn University Press, Bangkok.

Gao W., 1996. Analysis and performance of a solar air heater with cross corrugated absorber and back-plate, MS thesis, Yunnan Normal University, Kunming.

Gao, W., Lin, W., Lu, E., 2000. Numerical study on natural convection inside the channel between the flat-plate cover and sinewave absorber of a cross-corrugated solar air heater, Energy Conversion \& Management, Vol. 41, pp. 145-151.

Ho CD, Chen TC, 2006. The recycle effect on the collector efficiency improvement of double-pass sheet-and-tube solar water heaters with external recycle, Renew Energy, Vol. 31, No. 7, pp. 953-97.

Hetsroni G, Rozenblit R., 1994. Heat transfer to a liquid-solid mixture in a flume. Int. J. Multiph. Flow, Vol. 20, No. 4, pp. 671689.

Hussain A, 2006. The performance of a cylindrical solar water heater, Renew. Energy, Vol. 31, No. 11, 1751-1763.

Hwang Y, Lee JK, Lee CH, Jung YM, Cheong SI, Lee CG, Ku BC, Jang SP, 2007. Stability and thermal conductivity characteristics of nanofluids, Thermochimica Acta, Vol. 455 (1-2), pp. 70-74.

Kakaç, S and Pramuanjaroenkij, 2009. Review of convective heat transfer enhancement with nanofluids, Int. J. of Heat and Mass Transfer, Vol. 52, pp. 3187-3196.

Kent, EF., 2009. Numerical analysis of laminar natural convection in isosceles triangular enclosures for cold base and hot inclined walls, Mechanics Research Communications, Vol. 36, pp. 497-508.

Khanafer, K, Vafai, K, 2011. A critical synthesis of thermophysical characteristics of nanofluids, Int. J. Heat Mass Transfer, Vol. 54, pp. 4410-4428.

Kolb A, Winter ERF, Viskanta R., 1999. Experimental studies on a solar air collector with metal matrix absorber, Solar Energy, Vol. 65, No. 2, pp. 91-98.

Konttinen P, Lund PD, Kilpi RJ., 2003. Mechanically manufactured selective solar absorber surfaces, i, Vol. 79, No. 3, pp. $273-$ 283.

Lin, K.C., Violi, A., 2010. Natural convection heat transfer of nanofluids in a vertical cavity: Effects of non-uniform particle diameter and temperature on thermal conductivity, Int. J. of Heat and Fluid Flow, Vol. 31, pp. 236-245.

Lund KO., 1986. General thermal analysis of parallel-flow flat-plate solar collector absorbers, Solar Energy, Vol. 36, No. 5, pp. 443-450.

Mahian, O, Kianifar, A, Kalogirou, SA, Pop, I and Wongwises, S, 2013. A review of the applications of nanofluids in solar energy, Int. J. of Heat and Mass Transf., Vol. 57, pp. 582-594.

Maxwell-Garnett, J.C., 1904. Colours in metal glasses and in metallic films, Philos. Trans. Roy. Soc. A Vol. 203, pp. 385-420.

Molineaux B, Lachal B, Gusian O., 1994. Thermal analysis of five outdoor swimming pools heated by unglazed solar collectors, Solar Energy, Vol. 53, No. 1, pp. 21-26.

Nag A, Misra D, De KE, Bhattacharya A, Saha SK., 1989. Parametric study of parallel flow flat plate solar collector using finite element method, In: Numerical Methods in Thermal Problems, Proceedings of the $6^{\text {th }}$ International Conference, Swansea, UK.

Nasrin, R., Parvin, S. and Alim, MA., 2012a. Free convective phenomena in a tilted enclosure filled with water- $\mathrm{Al}_{2} \mathrm{O}_{3}$ nanofluid, International Journal of Engineering, Science \& Technology, Vol. 4, No. 3, pp. 1-14.

Nasrin, R. and Alim, MA., 2012b. Effect of radiation on convective flow in a tilted solar collector filled with water-alumina nanofluid, International Journal of Engineering, Science \& Technology,. Vol. 4, No. 4, pp. 1-12.

Nasrin, R., Alim, MA. and Chamkha, AJ., 2012c. Prandtl number variation on transient forced convection flow in a fluid valve using nanofluid, International Journal of Engineering, Science \& Technology, Vol. 4, No. 2, pp. 1-16.

Nasrin, R., Alim, MA. and Chamkha, AJ., 2013. Effects of physical parameters on natural convection in a solar collector filled with nanofluid, Heat Transfer-Asian Research, Vol. 42, No. 1, pp. 73-88.

Nasrin, R., Alim, MA. and Chamkha, AJ., 2012d. Effect of viscosity variation on natural convection flow of water-alumina nanofluid in an annulus with internal heat generation, Heat Transfer-Asian Research, Vol. 41, No. 6, pp. 536-552.

Noorshahi S, Hall CA, Glakpe EK., 1996. Natural convection in a corrugated enclosure with mixed boundary conditions, ASME Journal of Solar Energy Engineering, Vol. 118, pp. 50-57.

Ogut, EB., 2009. Natural convection of water-based nanofluids in an inclined enclosure with a heat source, International Journal of Thermal Sciences, Vol. 48, pp. 1-11.

Orel ZC, Gunde MK, Hutchins MG., 2002. Spectrally selective solar absorbers in different non-black colours, Proceedings of WREC VII, Cologne on CD-ROM. 
Pak, BC., Cho, Y., 1998. Hydrodynamic and heat transfer study of dispersed fluids with submicron metallic oxide particle, Experimental Heat Transfer, Vol. 11, pp. 151-170.

Piao Y, Hauptmann EG, Iqbal M., 1994. Forced convective heat transfer in cross-corrugated solar air heaters, ASME Journal of Solar Energy Engineering, Vol. 116, pp. 212-214.

Rohni, AM, Ahmad, S, Pop, I, 2011. Boundary layer flow over a moving surface in a nanofluid beneath a uniform free stream, Int. J. Numer. Methods Heat Fluid Flow, Vol. 21, pp. 828-846.

Rohni, AM, Ahmad, S, Pop, I, 2012. Flow and heat transfer over an unsteady shrinking sheet with suction in nanofluids, Int. J. Heat Mass Transfer, Vol. 55, pp. 1888-1895.

Rosca, AV, Rosca, NC, Grosan, T and Pop, I., 2012. Non-Darcy mixed convection from a horizontal plate embedded in a nanofluid saturated porous media, Int. Comm. in Heat Mass Transfer, Vol. 39, pp. 1080-1085.

Saidur, R, Kazi, SN, Hossain, MS, Rahman, MM, Mohammed, HA, 2011. A review on the performance of nanoparticles suspended with refrigerants and lubricating oils in refrigeration systems, Ren. Sustain. Energy Rev. Vol. 15, pp. 310-323.

Soltau H., 1992. Testing the thermal performance of uncovered solar collectors, Solar Energy, Vol. 49, No. 4, pp. $263-272$.

Stasiek JA., 1998. Experimental studies of heat transfer and fluid flow across corrugated-undulated heat exchanger surfaces, Int. J. of Heat and Mass Transfer, Vol. 41, pp. 899-914.

Sukhatme SP., 1991. Solar energy, principles of thermal collection and storage, New Delhi, Tata McGraw-Hill.

Taylor, C., Hood, P., 1973. A numerical solution of the Navier-Stokes equations using finite element technique, Computer and Fluids, Vol. 1, pp. 73-89.

Tripanagnostopoulos Y, Souliotis M, Nousia Th., 2000. Solar collectors with colored absorbers, Solar Energy, Vol. 68, pp. 343356.

Uddin, Md. J, Pop, I, Ismail, AI.Md., 2012. Free convection boundary layer flow of a nanofluid from a convectively heated vertical plate with linear momentum slip boundary condition, Sains Malaysiana, Vol. 41, pp. 1475-1482.

Varol, Y. and Oztop, HF., 2007. Buoyancy induced heat transfer and fluid flow inside a tilled wavy solar collector. Building Environment, Vol. 42, pp. 2062-2071.

Wazwaz J, Salmi H, Hallak R., 2002. Solar thermal performance of a nickel-pigmented aluminium oxide selective absorber, Renewable Energy, Vol. 27, pp. 277-292.

Wong, KFV and Leon, OD, 2010. Applications of nanofluids: Current and future, Adv. Mech. Eng. Article ID 519659.

Xiaowu W, Hua B, 2005. Energy analysis of domestic-scale solar water heaters, Renew. Sustain Energy Rev., Vol. 9, No. 6, pp. $638-645$.

Xuesheng W, Ruzhu W, Jingyi W, 2005. Experimental investigation of a new-style double-tube heat exchanger for heating crude oil using solar hot water, Appl. Therm. Eng., Vol. 25 (11-12), pp. 1753-1763.

\section{Biographical notes}

Rehena Nasrin received M. Sc. and M. Phil. from University of Dhaka and Bangladesh University of Engineering and Technology, Bangladesh in 2002 and 2009 , respectively. Now she is Assistant Professor in the Department of Mathematics, Bangladesh University of Engineering and Technology, Bangladesh. She is a Ph. D. student in Nanofluid with Computational Fluid Dynamics.

M. A. Alim received M. Phil. and Ph. D. from Bangladesh University of Engineering and Technology, Bangladesh and Loughborough University, Loughborough, Leicestershire, UK respectively. Now he is Professor in the Department of Mathematics, Bangladesh University of Engineering and Technology, Bangladesh. He is reviewer of more than twenty five international journals.

Received May 2012

Accepted March 2013

Final acceptance in revised form March 2013 